\title{
Nature and Nurture: Brain Region-Specific Inheritance of Sleep Neurophysiology in Adolescence
}

\author{
Thomas Rusterholz, ${ }^{1,2,3 *}$ @Christoph Hamann, ${ }^{1 *}$ @Andjela Markovic, ${ }^{1}$ Stefanie J. Schmidt, ${ }^{1,4}{ }^{\circledR P}$ Peter Achermann, ${ }^{2,5,6}$ \\ and $\oplus^{-L e i l a ~ T a r o k h}{ }^{1}$ \\ ${ }^{1}$ University Hospital of Child and Adolescent Psychiatry and Psychotherapy, University of Bern, Bern 3000, Switzerland, ${ }^{2}$ Institute of Pharmacology and \\ Toxicology, University of Zurich, Zurich 8057, Switzerland, ${ }^{3}$ Centre for Experimental Neurology, Department of Neurology, Inselspital University Hospital \\ Bern, University of Bern, Bern 3010, Switzerland, ${ }^{4}$ Department of Clinical Psychology and Psychotherapy, University of Bern, Bern 3012, Switzerland, \\ ${ }^{5}$ Zurich Center for Interdisciplinary Sleep Research, University of Zurich, Zurich 8091, Switzerland, and ${ }^{6}$ The KEY Institute for Brain-Mind Research, \\ Department of Psychiatry, Psychotherapy and Psychosomatics, University Hospital of Psychiatry, Zurich 8006, Switzerland
}

Sleep-specific oscillations of spindles and slow waves are generated through thalamocortical and corticocortical loops, respectively, and provide a unique opportunity to measure the integrity of these neuronal systems. Understanding the relative contribution of genetic factors to sleep oscillations is important for determining whether they constitute useful endophenotypes that mark vulnerability to psychiatric illness. Using high-density sleep EEG recordings in human adolescent twin pairs ( $n=60 ; 28$ females), we find that over posterior regions $80-90 \%$ of the variance in slow oscillations, slow wave, and spindle activity is due to genes. Surprisingly, slow (10-12 $\mathrm{Hz})$ and fast $(12-16 \mathrm{~Hz})$ anterior spindle amplitude and $\sigma$ power are largely driven by environmental factors shared among the twins. To our knowledge this is the first example of a neural phenotype that exhibits a strong influence of nature in one brain region, and nurture in another. Overall, our findings highlight the utility of the sleep EEG as a reliable and easy to measure endophenotype during adolescence. This measure may be used to measure disease risk in development before the onset of a psychiatric disorder; the location within the brain of deficits in sleep neurophysiology may suggest whether the ultimate cause is genetic or environmental.

Key words: adolescent; EEG; sleep; twin

\section{Significance Statement}

Two cardinal oscillations of sleep, slow waves and sleep spindles, play an important role in the core functions of sleep including memory consolidation, synaptic plasticity, and the recuperative function of sleep. In this study, we use a behavioral genetics approach to examine the heritability of sleep neurophysiology using high-density EEG in a sample of early adolescent twins. Our findings reveal a strong influence of both environmental and genetic factors in shaping these oscillations, dependent on brain region. Thus, during a developmental period when brain structure and function is in flux, we find that the sleep EEG is among the most heritable of human traits over circumscribed brain regions.

\section{Introduction}

Studying the sleeping brain has recently been recognized as a powerful method to understand neural function. Compared with

\footnotetext{
Received April 18, 2018; revised Aug. 29, 2018; accepted Sept. 1, 2018.

Author contributions: P.A. and L.T. edited the paper; L.T. wrote the first draft of the paper; L.T. designed research; C.H. and L.T. performed research; T.R., C.H., A.M., S.J.S., and L.T. analyzed data; L.T. wrote the paper.

This work was supported by a Grant from the Jacobs Foundation (L.T.).We thank Nathaline Margot, Daniela Rupp, Tammy Timmers, Stephanie Leuenberger, and Julia Hegy for data collection; the participants and their families for participating in the study; A. Borbély and I. Tobler for continual fruitful discussions (from L.T.); Dr. Roland Dürr for support with the EEG data processing; and Dr. Ben Collins for commenting on the paper.

The authors declare no competing financial interests.

*T.R. and C.H. contributed equally to this work as co-first authors.

Correspondence should be addressed to Dr. Leila Tarokh, University Hospital of Child and Adolescent Psychiatry and Psychotherapy, University of Bern, Bolligenstrasse 111, Haus A, 3000 Bern 60, Switzerland. E-mail: leila.tarokh@upd.unibe.ch.
}

waking measures, which are susceptible to both internal (e.g., attention) and external influences (Kitsune et al., 2015), the sleep EEG offers a stable state that is unaffected by such factors. Over the last decade a functional role of sleep-specific oscillations in sleep-dependent learning, synaptic plasticity, and the recuperative function of sleep have been found (Abel et al., 2013). One such oscillation is the sleep spindle: waxing and waning bursts in the sleep EEG between 11 and $16 \mathrm{~Hz}$. Sleep spindles are generated through thalamocortical loops and thus are a valuable and unique marker of the integrity of this system in humans (Huguenard and McCormick, 2007; Andrillon et al., 2011). Deficits in 
sleep spindles have been reported in many patient populations. For example, significantly diminished sleep spindles have been found in schizophrenic patients (for review, see Manoach et al., 2016; Ferrarelli and Tononi, 2017). Interestingly, in contrast to equivocal findings with regard to other neurophysiological markers, the deficits in sleep spindles are consistent across studies suggesting a potentially powerful endophenotype (Manoach et al., 2016).

Spindles are not only associated with disordered brains. Several lines of research have identified a role of sleep spindles in cognitive processes. For example, greater spindle activity has been associated with a higher intelligence quotient (for review, see Ujma et al., 2016) and spindles have been shown to be beneficial for memory formation and learning (for review, see Lüthi, 2014). Due to this link and based on work in animals showing that spindles can induce postsynaptic long-term potentiation (Rosanova and Ulrich, 2005), spindles have been hypothesized to be important for synaptic plasticity in the healthy brain.

Another key sleep oscillation implicated in sleep-dependent recovery are slow waves; high-amplitude, low-frequency oscillations that are homeostatically regulated. Slow waves originate in the cortex and propagate by corticocortical and corticothalamocortical connections (Steriade, 2006). Slow waves are locally intensified in a use-dependent manner; if a cortical region is extensively used during the waking day, that region will exhibit greater slow-wave activity (SWA) in the subsequent sleep episode (Huber et al., 2004). Slow waves are hypothesized to be responsible for the recuperative function of sleep, downscaling synapses that are potentiated during the waking day as a result of learning (Tononi and Cirelli, 2006). Aberrations in SWA have been reported for several psychiatric and neurological disorders including depression (Tesler et al., 2016), schizophrenia (Keshavan et al., 1998; Sekimoto et al., 2007), and Alzheimer's disease (Mander et al., 2015).

Together, the above findings paint a picture highlighting the importance of sleep spindles and slow waves as a window onto corticocortical and thalamocortical function in health and disease. Adding to the utility of sleep EEG oscillations is the stability of this measure over time (De Gennaro et al., 2005; Buckelmüller et al., 2006; Tinguely et al., 2006; Bódizs et al., 2009; Tarokh et al., 2011; Benz et al., 2013; Bersagliere et al., 2018). Furthermore, two twin studies in adults have shown that the sleep EEG is highly heritable. One limitation of these studies is the use of a one (left central; Ambrosius et al., 2008) to three (midline frontal, central, and parietal; De Gennaro et al., 2008) EEG derivations. The sleep EEG shows strong topographic variation dependent on frequency band; in adults, SWA is maximal over frontal regions, whereas sleep spindles are maximal over central regions (Finelli et al., 2001). Therefore, as is seen in MRI twin studies (Lenroot et al., 2009) of gray and white matter volume, the genetic contribution may vary dependent on brain region.

Although much has been gained from studying the heritability of the sleep EEG in adults, there are several reasons to study adolescent sleep neurophysiology. For one, many neuropsychiatric disorders have their onset during adolescence (Fatemi and Folsom, 2009). Furthermore, the search for endophenotypes to measure vulnerability to an illness is arguably most fruitful during development given the higher degree of plasticity in adolescence and the higher efficacy of interventions in this developmental phase. Finally, during adolescence the brain undergoes rapid restructuring (Giedd et al., 2015) manifest in the sleep EEG as a steep decline in power (Buchmann et al., 2011). Therefore,
Table 1. Mean and SD of sleep-stage variables along with estimates for genes (A), shared environmental factors (C), and unique environmental factors/measurement error $(E)$ influences to sleep-stage parameters

\begin{tabular}{lclll}
\hline & Mean (SD) & Genes (A) & $\begin{array}{l}\text { Shared } \\
\text { Environment (C) }\end{array}$ & $\begin{array}{l}\text { Unique Environment/ } \\
\text { Error (E) }\end{array}$ \\
\hline Sleep efficiency, \% & $91.71(5.05)$ & 0.32 & 0 & 0.86 \\
Sleep latency, min & $20.56(15.08)$ & 0.72 & 0 & 0.27 \\
REM sleep, min & $141.32(35.68)$ & 0 & 0.19 & 0.81 \\
REM sleep latency, min & $104.53(43.57)$ & 0.40 & 0 & 0.60 \\
Stage 1, min & $3.26(5.37)$ & 0 & 0.85 & 0.15 \\
Stage 2, min & $237.23(52.76)$ & 0 & 0.43 & 0.57 \\
Slow-wave sleep, min & $150.36(45.75)$ & 0.37 & 0 & 0.63 \\
Total sleep time, min & $532.18(47.26)$ & 0.02 & 0 & 0.98 \\
Wake after sleep onset & $26.51(27.71)$ & 0.32 & 0 & 0.68
\end{tabular}

With few exceptions, most of the variance for sleep-stage parameters is absorbed by unique environmental factors/ measurement error (E). Minutes of Stage 1 sleep showed a large influence of shared environmental factors (C), whereas sleep latency was genetically determined.

findings regarding the heritability of the sleep EEG in adults cannot be generalized to adolescents. The aim of this study was to use high-density sleep EEG recordings in twins to quantify the heritability of sleep neurophysiology in early adolescence across brain regions.

\section{Materials and Methods}

Participants and recording. High-density sleep EEG data (58 channels) were recorded in 18 ( $n=36 ; n=18$ females) monozygotic (MZ) and 12 ( $n=24 ; n=12$ females) same-sex dizygotic (DZ) twin pairs. A single triplet pair consisting of a MZ pair and DZ were included in both the MZ and DZ analyses. Most participants $(n=49)$ were between the ages of 12 and 14 years, the remaining participants were 11 years old, thus the mean age of the sample was 12.46 ( $S D=1.36$ ) years. Participants were healthy, born in the 30th gestation week or later, and in general were good sleepers. Sleep EEG, EOG (right and left), EMG (mentalis and submentalis), and ECG were recorded using a modified version of the electrical geodesics (EGI) 64 channel system.

Protocol. Two consecutive nights of sleep EEG were recorded (an adaptation night followed by a baseline night) in participants homes. Precautions were taken to minimize exposure to outside light and sound. Before recordings, participants spent at least $5 \mathrm{~d}$ on a stabilization schedule (based on school start time), ensuring time in bed between 9.5 and $10 \mathrm{~h}$ and thus adequate sleep. Compliance to the sleep schedule was determined via actigraphy and sleep diary. Caffeine intake was prohibited for $3 \mathrm{~d}$ before and during the study.

Analysis. Analyses were performed on the baseline night of sleep with the exception of three subjects in which the adaptation night was used due to insufficient data quality on the baseline night. Data were scored according to standard criteria (Rechtschaffen and Kales, 1968).

Data were high-pass filtered (subtracting sliding median across $10 \mathrm{~s}$ ), low-pass filtered at $100 \mathrm{~Hz}$ (Fourier filter: FFT of EEG followed by setting of frequencies $>100 \mathrm{~Hz}$ to 0 and then performing an inverse FFT) and downsampled to $250 \mathrm{~Hz}$ (collected at $1000 \mathrm{~Hz}$ ). EEGs were re-referenced to average reference, excluding channels with poor quality. Bad channels were individually identified by visual inspection of the spectrograms calculated with the acquisition reference. Power density spectra were calculated for $30 \mathrm{~s}$ epochs using Welch's method ( $5 \mathrm{~s}$ sub-epochs, Hanning window, no overlap). Artifacts were excluded semiautomatically, whenever power exceeded a threshold based on a moving average over 21 epochs for the frequency bands $0.8-4.6$ and $20-40 \mathrm{~Hz}$ (Buckelmüller et al., 2006). NREM sleep EEG power for the following bands were used for analysis: slow oscillations (SOs; $0.6-1.2 \mathrm{~Hz}$ ), SWA $(1.4-4.6 \mathrm{~Hz}$ ), theta $(4.8-7.8 \mathrm{~Hz}), \alpha(8-10.8 \mathrm{~Hz}), \sigma(11-16 \mathrm{~Hz})$, beta $1(16.2-20 \mathrm{~Hz})$, beta 2 $(20.2-24 \mathrm{~Hz})$, gamma $1(24.2-34 \mathrm{~Hz})$, and gamma $2(34.2-44 \mathrm{~Hz})$.

In addition to examining the above bands, we used a spindle detection algorithm to detect and characterize individual spindles. The algorithm we used was similar to (Ferrarelli et al., 2007); however, instead of the rectified bandpass filtered signal we used the envelope of the bandpass 

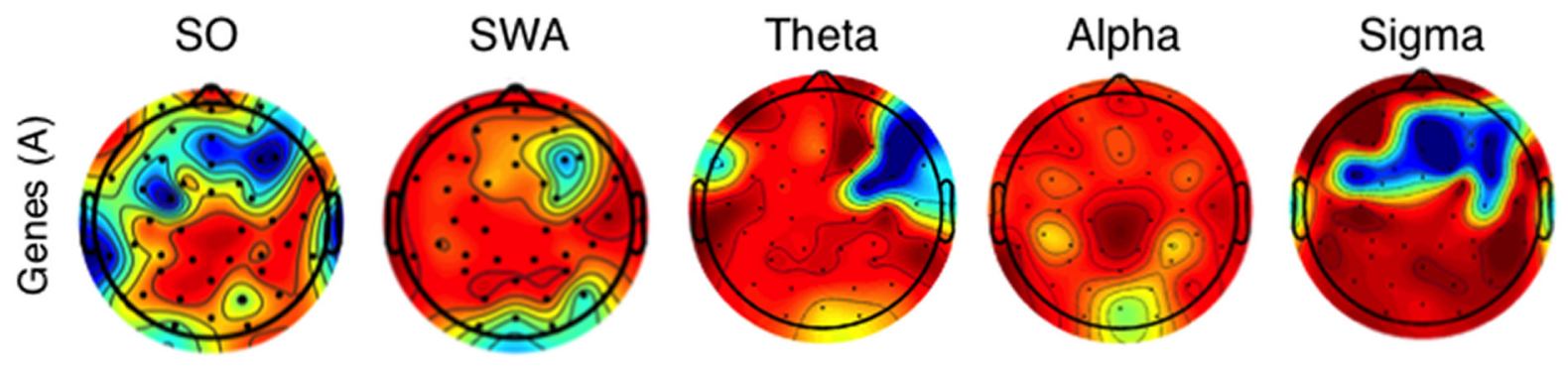

$\operatorname{Max}$
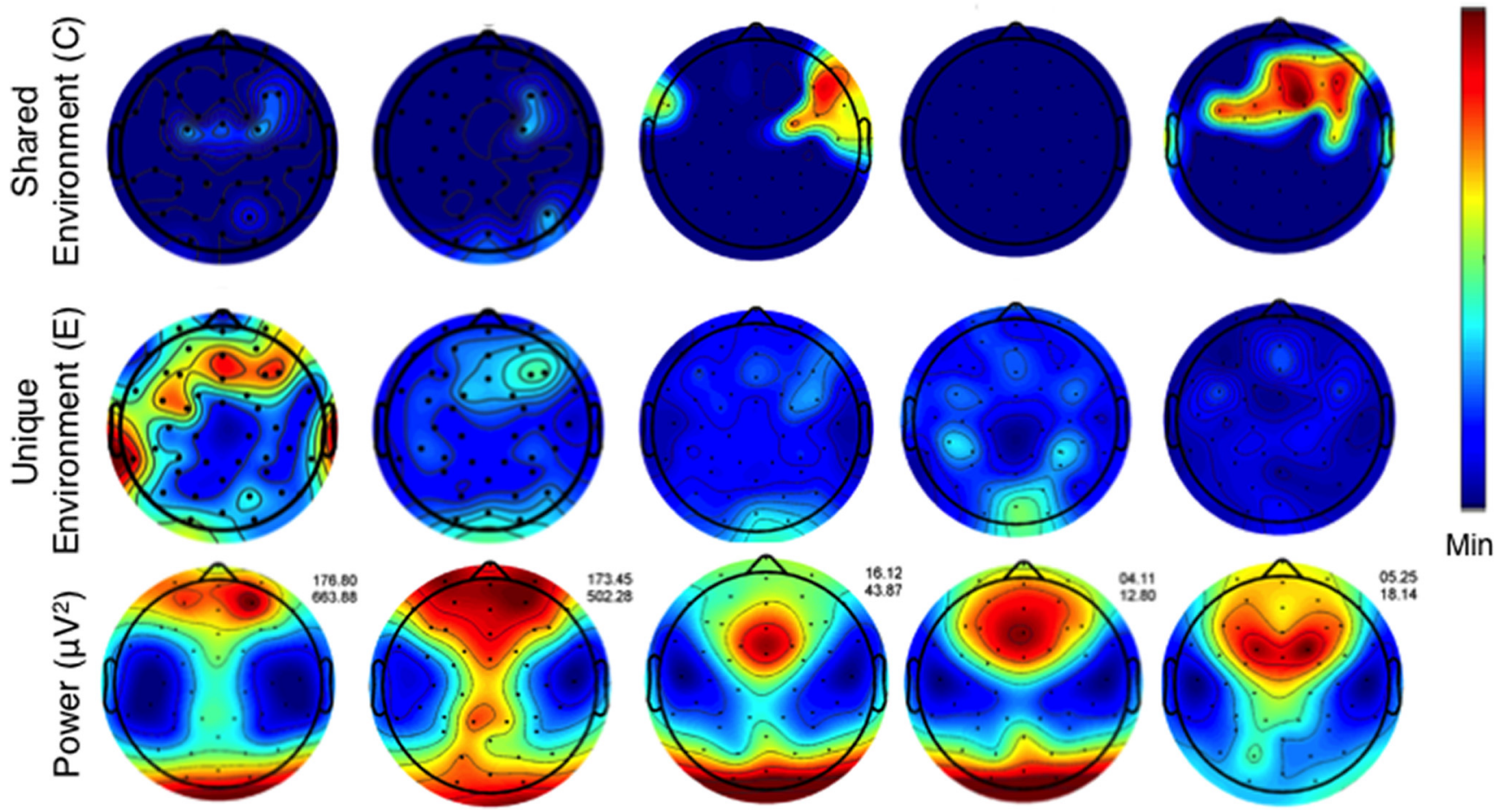

Min

Figure 1. Top three rows depict results from the SEM analysis. In these topographic maps the amount of variance (percentage) explained by $\mathrm{A}, \mathrm{C}$, and E contributors to SOs ( $0.6-1.2 \mathrm{~Hz}$ ), SWA $(1.4-4.6 \mathrm{~Hz})$, theta $(4.8-7.8 \mathrm{~Hz}), \alpha(8-10.8 \mathrm{~Hz})$, and $\sigma(11-16 \mathrm{~Hz})$ power in NREM sleep is shown. Data for SEM analyses are scaled from 0 to $100 \%$ and warm colors indicate that a large portion of the variance is explained by the plotted factor, whereas cool colors indicate little or no contribution to the variance of the plotted factor. The bottom (i.e., fourth) row shows the topographic distribution of power averaged across all subjects (independent of twin status). The minima and maxima for each of these maps are shown in microvolts squared at the top right of the map. Electrode locations are shown with a black dot in all topographic maps.

filtered signal derived from the Hilbert transform with an upper threshold of 6 and a lower threshold of 2 based on Warby et al. (2014) and McClain et al. (2016). We then divided spindles into slow $(>10$ but $<12$ $\mathrm{Hz}$ ) and fast ( $\geq 12$ and $\leq 16 \mathrm{~Hz}$ ) spindles, because separate mechanism of generation and function have been attributed to these two spindle classes. Furthermore, slow and fast spindles show topographic segregation with fast spindles prevailing over posterior regions and slow spindles over anterior regions (Werth et al., 1997; Bersagliere et al., 2018). For each class of spindles we quantify amplitude, duration, density, and integrated spindle activity (ISA), which is obtained by integrating the absolute amplitude over the duration of each spindle (Ferrarelli et al., 2010).

Statistics. To differentiate between genetic and environmental factors, structural equation modeling (SEM) with OpenMx in R (Boker et al., 2011) was used. SEM is a standard tool used in twin research as it allows for the quantification of latent factors (e.g., genes and environment) to be made based on observed data. The estimation of latent factors is achieved based on the assumption that the genetic concordance between MZ twins is 1 , whereas it is 0.5 in DZ twins. On the other hand, both MZ and DZ twins share a familial and school environment, therefore the shared environmental concordance is 1 for both $\mathrm{MZ}$ and $\mathrm{DZ}$ twins. Unique environmental factors are factors that are uncorrelated among both $\mathrm{MZ}$ and DZ twins. Based on these assumptions a path diagram can be built that can estimate the contribution of genetic factors (A), shared environmental factors $(\mathrm{C})$, and unique environmental factor and measurement error
(E). A, C, and E can vary between 0 and 1 and sum to 1 , with 1 indicating that $100 \%$ of the variance is due to that factor. In some cases, estimates of $\mathrm{C}$ or A were close to zero and the full model (ACE) exhibited the highest Akaike information criterion, a measure of the goodness of fit of the model where lower values indicate a better fit. In these instances, the analysis was redone excluding the estimate that was close to zero (and nonsignificant) to achieve a better fit of the model (Evans et al., 2002; Rijsdijk and Sham, 2002).

To make our results comparable to the findings of the two previous twin studies conducted in adults, we also conducted an intraclass correlation coefficient (ICC) analysis. Furthermore, in the twin literature, Falconers heritability, $h^{2}$, defined as $2\left(r_{\mathrm{Mz}}-r_{\mathrm{DZ}}\right)$, where $r_{\mathrm{Mz}}$ and $r_{\mathrm{DZ}}$ are the correlation within $\mathrm{MZ}$ and $\mathrm{DZ}$ twin pairs, respectively, is typically used. Therefore, we also used this metric. We note, however, that these two measures yield very similar results, with the primary difference being that correlation coefficients (i.e., Falconers heritability) do not take intersubject variability into account. Compared with SEM, these analyses cannot tease apart the genetic from the environmental influence on a given phenotype. Rather, they are a measure of the similarity between MZ compared with DZ twins with the assumption that greater similarity between $M Z$ twin pairs compared with $\mathrm{DZ}$ twins is because of the higher proportion of shared genes among MZ twins.

For both ICC and correlation analysis, we used a bootstrap statistic whereby all MZ twins were pooled independent of twin status. Two 

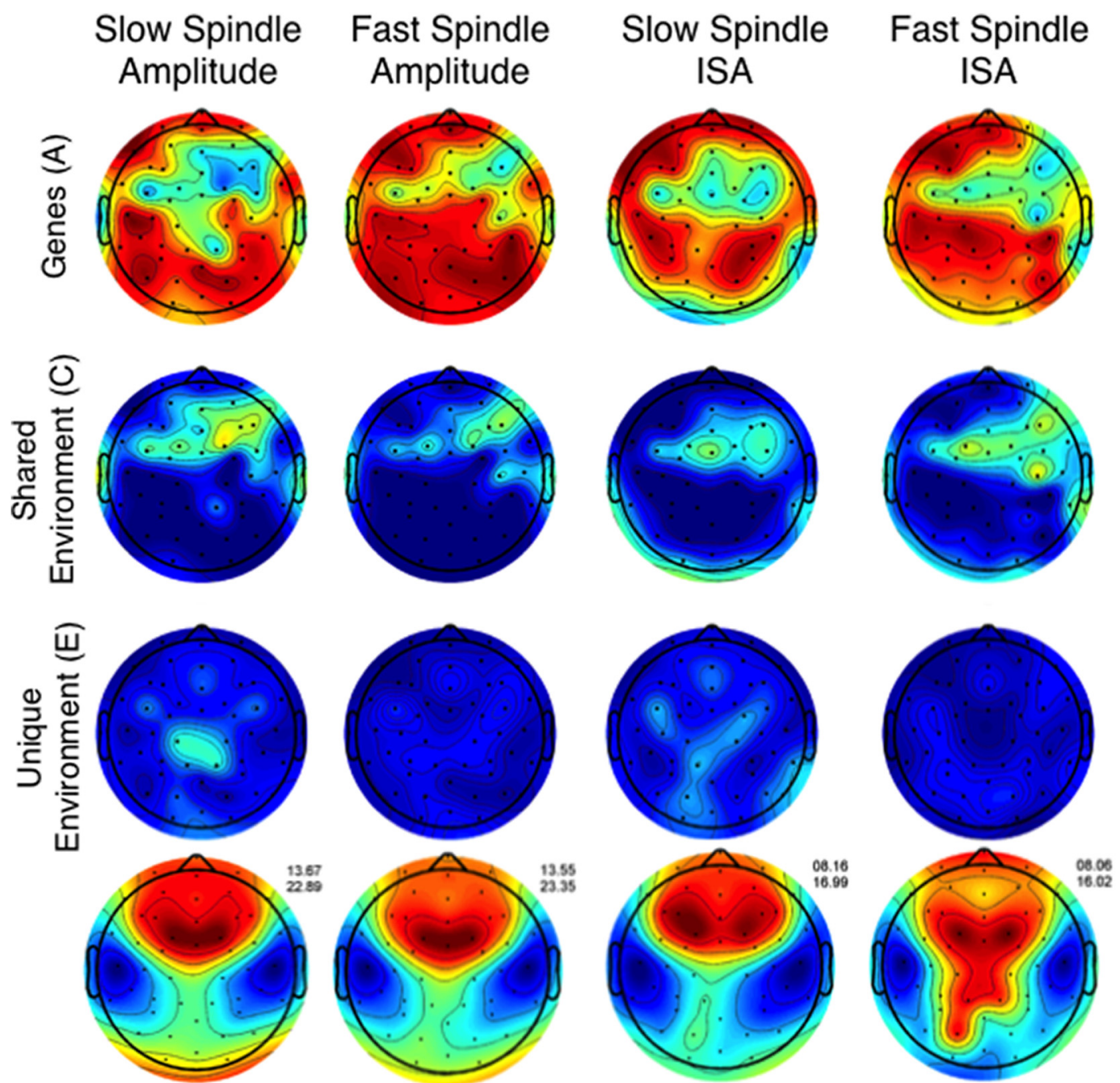

\section{$\operatorname{Max}$}

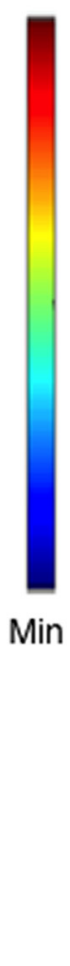

Figure 2. Top three rows depict results from the SEM analysis. In these topographic maps the amount of variance (percentage) explained by A, C, and E to slow (10 - $12 \mathrm{~Hz}$ ) and fast ( $12-16 \mathrm{~Hz}$ ) sleep-spindle amplitude and ISA is shown. Data for SEM analyses are scaled from 0 to $100 \%$ and warm colors indicate that a large portion of the variance is explained by the plotted factor, whereas cool colors indicate little or no contribution to the variance of the plotted factor. The bottom (i.e., fourth) row shows the topographic distribution of spindle amplitude (measured in microvolts) and ISA (measured in microvolts per second) averaged across all subjects (independent of twin status). The minima and maxima for each of these maps are shown at the top right of the map. Electrode locations are shown with a black dot in all topographic maps.

groups were randomly drawn from this pool and the correlation coefficient/ICCs between these groups were calculated. This procedure was repeated 1000 times resulting in a distribution of the $r$ and ICC values. The $r$ and ICC values obtained from the observed dataset were then compared with the distribution obtained from random sampling. A $p$ value was defined as the number of instances where the value obtained from random sampling was larger than that observed in the data divided by 1000 . In this way, we can calculate the probability of obtaining our results by chance and control the familywise error rate (Maris and Oostenveld, 2007; Pernet et al., 2015). The same procedure was performed for DZ twins.

\section{Results}

Structural equation modeling: sleep stages

Participants slept well (sleep efficiency $>90 \%$ ), showed an average sleep latency $(21 \mathrm{~min})$ typical for this age group, and slept $\sim 8.9 \mathrm{~h}$ (Table 1). SEM analysis revealed that most sleep-stage variables did not show a strong genetic or shared environmental influence (Table 1). Exceptions to this were sleep latency, which showed a strong genetic contribution $(\mathrm{A}=0.73)$. Furthermore, wake after sleep onset $(\mathrm{A}=0.32)$, duration of slow-wave sleep $(\mathrm{A}=0.37)$, REM sleep latency $(\mathrm{A}=0.40)$, and sleep efficiency
$(\mathrm{A}=0.32)$ showed moderate genetic influence. A shared environmental influence was found for the duration of Stage $1(\mathrm{C}=$ $0.85)$ and Stage $2(\mathrm{C}=0.43)$ sleep.

\section{Structural equation modeling: EEG power}

Strong genetic contributions to slow oscillations were observed over central, temporal, parietal and occipital regions (30 derivations with an estimate of A between 61 and 89\%; Fig. 1). Conversely, unique environmental factors accounted for the variance in SOs over frontal and left temporal regions (16 derivations with an estimate of E between 51 and 90\%). With regard to SWA, a measure of sleeps recuperative process, we find that it is under high genetic control ( $\mathrm{A}$ in model, standardized estimates of $60-93 \%$ of the variance due to genes for 44 derivations) over widespread cortical regions (Fig. 1). Similar to SOs, we find a contribution of unique environmental factors to variance over right frontal derivations ( $\mathrm{E}$ in model, $30-44 \%$ of variance because of unique environment; 12 EEG derivations). Accordingly, we find minimal contribution of shared environment to SWA and SOs.

Using $\sigma$ power $(11-16 \mathrm{~Hz})$ as one proxy for spindles (Dijk et al., 1993; Warby et al., 2014), we find that posterior spindles (19 


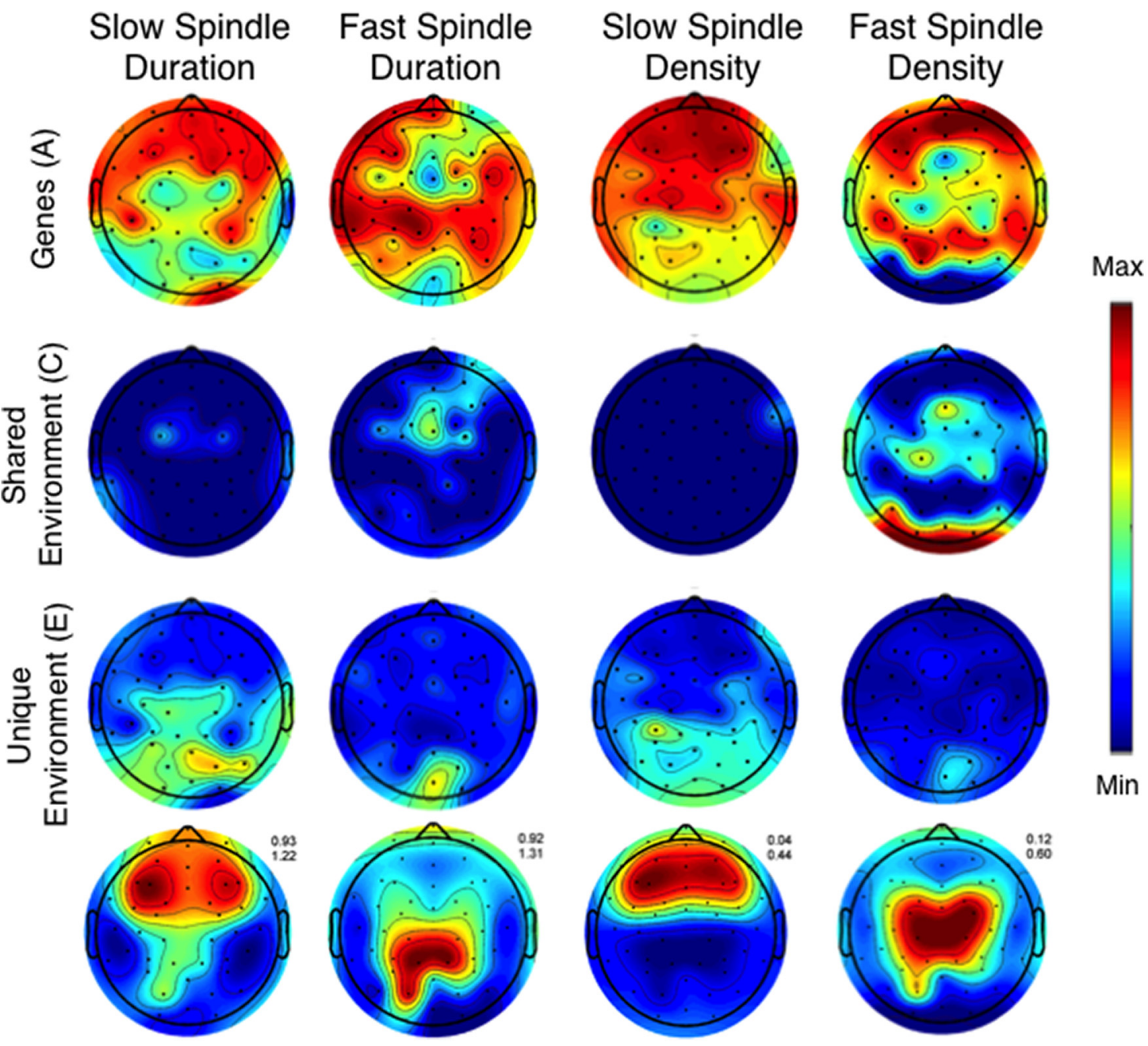

Figure 3. Top three rows depict results from the SEM analysis. In these topographic maps depicting the amount of variance (\%) explained by A, C, and E to slow (10 - $12 \mathrm{~Hz})$ and fast (12-16 Hz) sleep-spindle duration and density is shown. Data for SEM analyses are scaled from 0 to $100 \%$ and warm colors indicate that a large portion of the variance is explained by the plotted factor, whereas cool colors indicate little or no contribution to the variance of the plotted factor. The bottom (i.e., fourth) row shows the topographic distribution of spindle duration (measured in seconds) and density (spindles/min) averaged across all subjects (independent of twin status). The minima and maxima for each of these maps are shown at the top right of the map. Electrode locations are shown with a black dot in all topographic maps.

derivations) show strong genetic modulation (A), and no impact of shared environment $(\mathrm{C}=0)$ with estimates of A between 88 and $97 \%$ (Fig. 1). On the other hand, $\sigma$ power recorded at frontal/ frontal-central sites (7 derivations; red areas) show strong shared environmental modulation with estimates of $\mathrm{C}$ between $79-$ $81 \%$, with small genetic impact $(\mathrm{A}<20 \%)$. We find a similar pattern of results when using individually detected spindles parsed into two classes based on frequency (i.e., slow and fast spindles). For both fast and slow spindles, amplitude and ISA showed a contribution of shared environmental factors over frontal/frontal-central sites (Fig. 2), although the estimated environmental contribution was qualitatively less than that observed for $\sigma$ power (amplitude low spindles: 14 derivations with estimates of $\mathrm{C}$ between 42 and 60\%; amplitude fast spindles: 11 derivations with estimates of $\mathrm{C}$ between 40 and 52\%; ISA slow spindles: 5 derivations with estimates of $\mathrm{C}$ between 40 and $50 \%$; ISA fast spindles: 12 derivations with estimates of $\mathrm{C}$ between 40 and $61 \%)$.

With regard to the duration of slow spindles (Fig. 3) we observe a strong genetic contribution over frontal/central regions (32 derivations with estimates of A between 60 and $88 \%$ ) and a unique environmental contribution over posterior regions (11 derivations with estimates of $\mathrm{E}$ between 50 and $79 \%$ ). On the other hand, the duration of fast spindles was largely genetically driven ( 42 derivations with estimates of A between 60 and 89\%) but showed a contribution of shared environmental factors over frontal/frontal-central sites ( 6 derivations with estimates of $\mathrm{C}$ between 40 and 53\%). The topographic pattern of genetic and environmental factors to spindle density mirrored that of spindle duration, with slow spindles showing a contribution of unique environmental factors over posterior regions (10 derivations with estimates of $\mathrm{E}$ between 40 and $61 \%$ ), whereas fast spindles showed a contribution of shared environmental factors over frontal/central and occipital regions (15 derivations with estimates of $C$ between 40 and 98\%).

Power in the theta band also showed both strong genetic and shared environmental influences (Fig. 1). Derivations over lateral frontal/parietal regions $(n=10)$ showed nearly equal contribution of shared environmental and genetic impact, i.e., $\sim 50 \%$ of the variance explained by each factor. Elsewhere, power in this band was predominantly determined by genetic factors $(n=26$ 

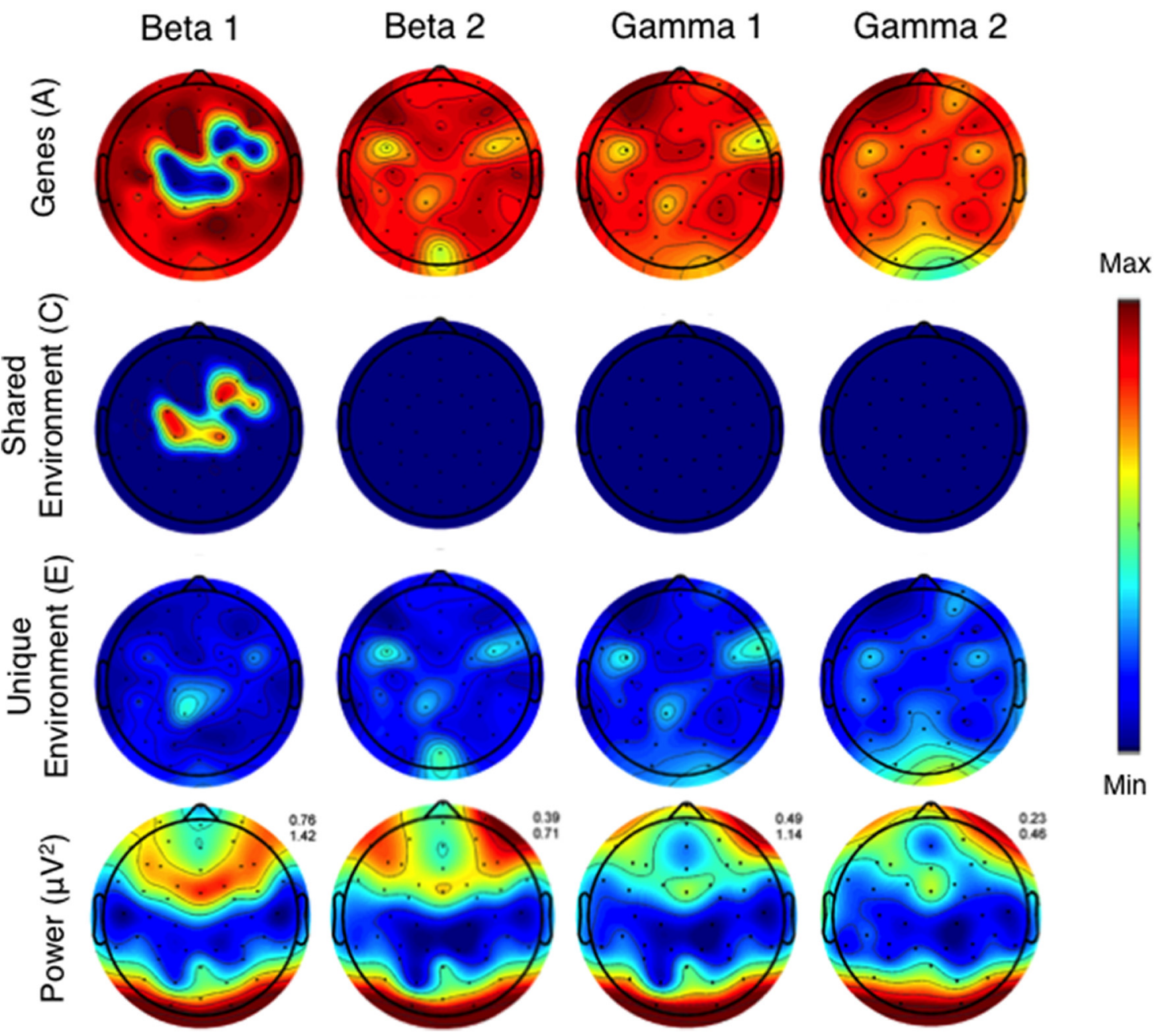

Figure 4. Top three rows depict results from the SEM analysis. In these topographic maps depicting the amount of variance explained by A, C, and E to beta $1(16.2-20 \mathrm{~Hz})$, beta $2(20.2-24 \mathrm{~Hz})$, gamma $1(24.2-34 \mathrm{~Hz})$, and gamma $2(34.2-44 \mathrm{~Hz})$ power in NREM sleep is shown. Data for SEM analyses are scaled from 0 to $100 \%$ and warm colors indicate that a large portion of the variance is explained by the plotted factor, whereas cool colors indicate little or no contribution to the variance of the plotted factor. The bottom (i.e., fourth) row shows the topographic distribution of power averaged across all subjects (independent of twin status). The minima and maxima for each of these maps are shown in microvolts squared at the top right of the map. Electrode locations are shown with a black dot in all topographic maps.

derivations with a range between 70 and $93 \%$ of the variance due to genes).

EEG power in the other frequency bands was almost entirely heritable (Figs. 1, 4): $\alpha$ ( $n=47$ derivations with $70-96 \%$ of the variance due to genes), beta 1 ( $n=36$ derivations with $70-97 \%$ of the variance due to genes), beta 2 ( $n=45$ with $70-96 \%$ of the variance due to genes), gamma 1 ( $n=40$ with 70 and $94 \%$ of the variance due to genes), and gamma $2(n=36$ with $70-93 \%$ of the variance due to genes).

Generally speaking, we found no correspondence between the topographic distribution of power, sleep spindle parameters, and heritability measures (Figs. 1-4, bottom rows). An exception to this was $\sigma$ power where the region with maximal power roughly corresponds with regions showing an influence of shared environmental factors.

Falconers heritability $\left(h^{2}\right)$ and ICCs

The results of Falconers heritability and the ICC analysis were similar to the SEM analysis (Figs. 5, 6). Correlation coefficients were high and statistically significant for MZ twin pairs across electrodes and bands (Figs. 5, 6). On the other hand, for DZ twin pairs, high and significant correlation coefficients were found for theta, $\alpha, \sigma$, beta 1 , and beta 2 bands only for specific derivations. Thus, although not as clearly circumscribed as the SEM analyses, topographic variation in heritability estimates was found using Falconers estimate [i.e., $\left.h^{2}=2\left(r_{\mathrm{Mz}}-r_{\mathrm{DZ}}\right)\right]$. For SOs and theta to beta 2 , heritability estimates were higher over posterior compared with anterior regions. For gamma 1 and gamma 2, heritability estimates were consistently high across the entire scalp. As expected, the spatial distribution of ICCs mirrored those of the correlation analysis (Figs. 5, 6).

\section{Discussion}

This is the first study to examine the heritability of the sleep EEG in a sample of adolescent twins. Due to the steep decline in sleep EEG power and neurodevelopmental changes during adolescence, heritability findings in adults cannot be extrapolated to adolescents. Developmental changes in heritability of many traits have been well documented, likely due to changes in age-related gene expression patterns (Yang et al., 2016). A meta-analysis reviewing the heritability of human traits from 2748 twin studies found significant age-related changes in heritability (Polderman et al., 2015). For example, MRI studies have shown a developmental progression in the heritability of gray and white matter 


\section{NREM Sleep: Correlations}
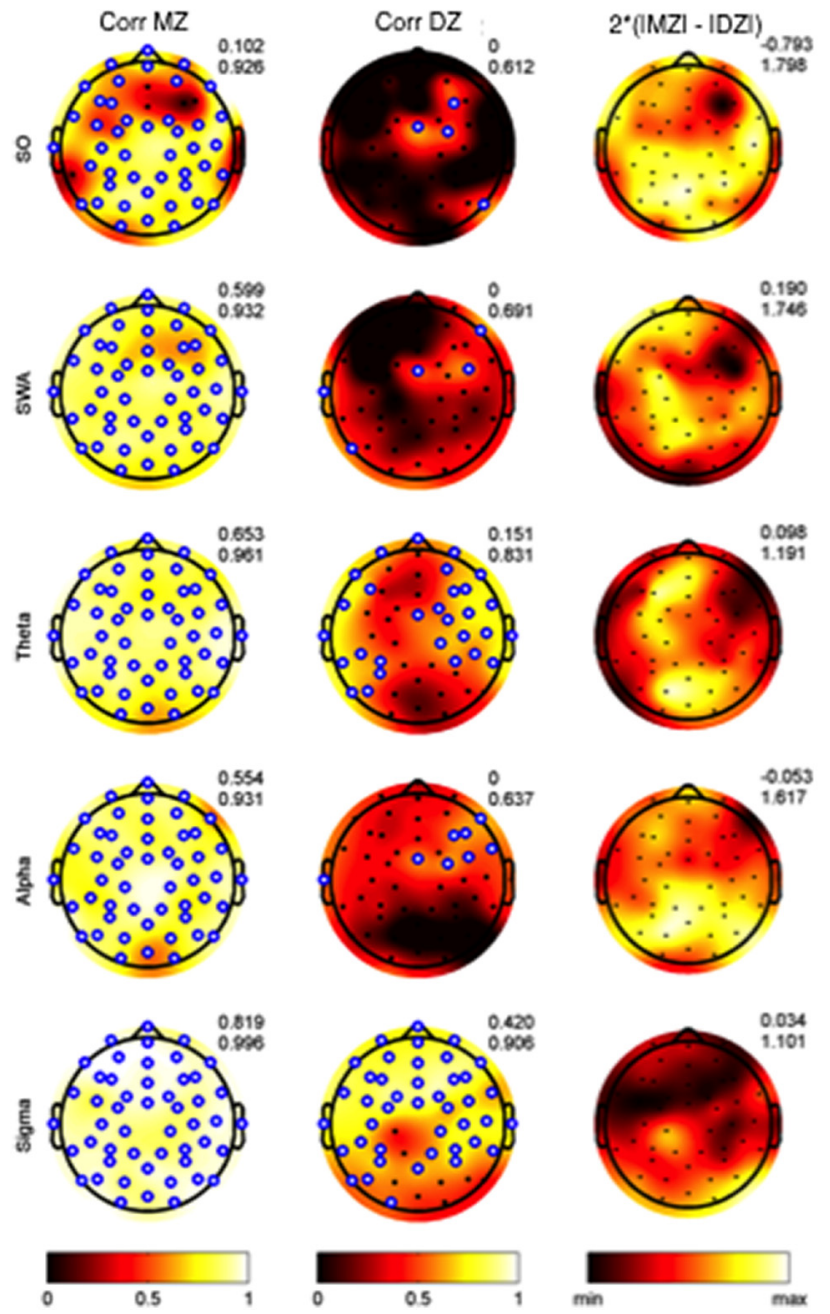

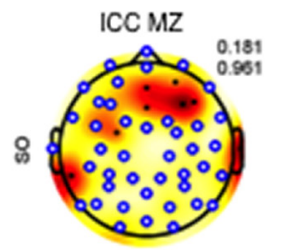

NREM Sleep: ICC
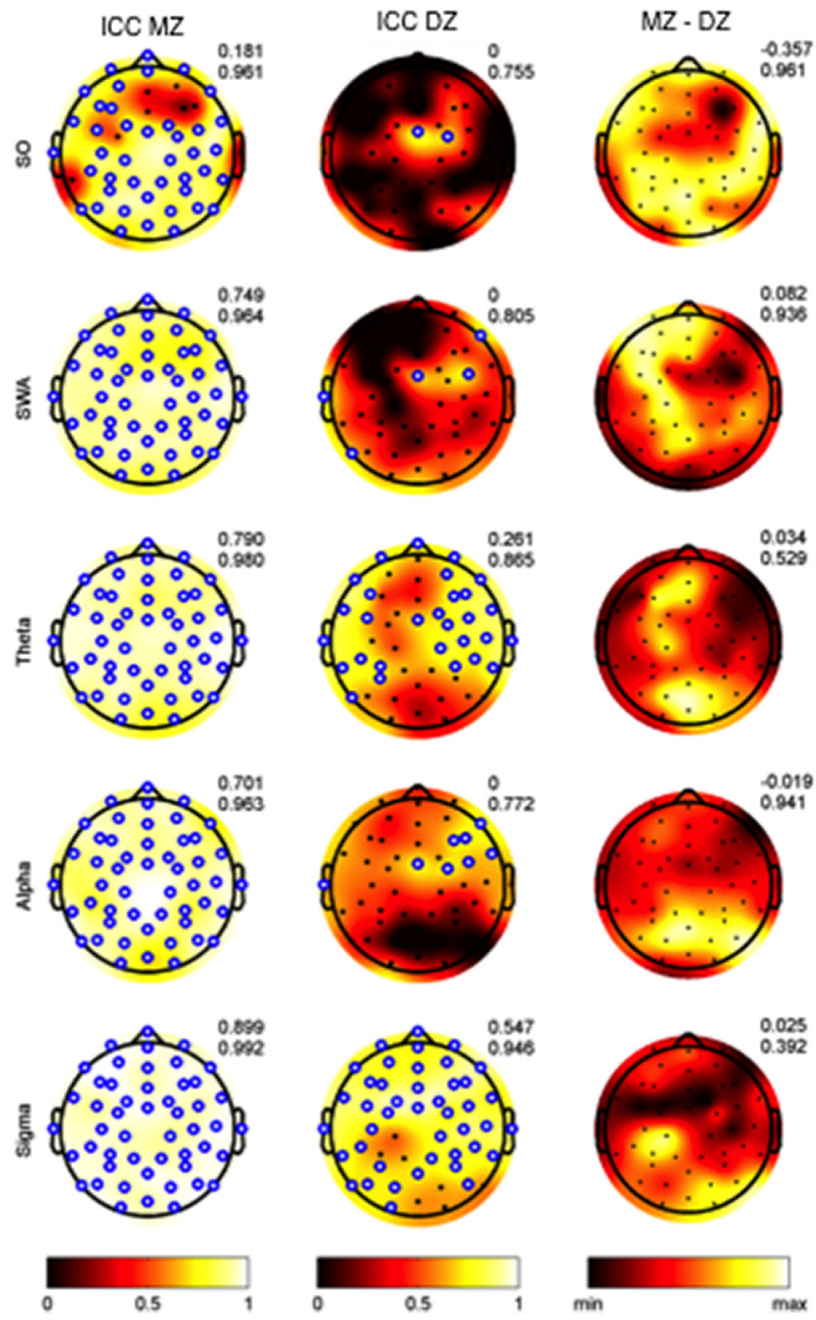

Figure 5. Pearson correlation coefficients (Corr; 3 leftmost plots) and ICCs ( 3 rightmost plots) for MZ and DZ twins for SOs ( $0.6-1.2 \mathrm{~Hz}), \mathrm{SWA}(1.4-4.6 \mathrm{~Hz})$, theta $(4.8-7.8 \mathrm{~Hz}), \alpha(8-10.8 \mathrm{~Hz})$, and $\sigma(11-16 \mathrm{~Hz}$ ) power. Derivations exhibiting a significant correlation coefficient ( $r$ value) or ICC based on bootstrap statistic are shown with a blue circle, whereas nonsignificant correlations are shown with a black dot. Falconers heritability $\left(h^{2}\right)$ is shown in the last column for the correlation maps and the difference in ICC values between MZ and DZ twins is shown for the ICC maps (MZ DZ). Correlation and ICC maps were scaled between 0 and 1 because negative correlations and ICC values are not biologically meaningful and likely reflect noise. The difference in ICC values between MZ and DZ twins (i.e., MZ - DZ) and $h^{2}[$ [i.e., $2 \times(|\mathrm{MZ}|-|\mathrm{DZ}|)]$ for correlation coefficients are scaled between minima (min) and maxima (max); however, we note that negative values (i.e., instance where ICC and correlation values are larger in DZ compared with MZ twins are not biological meaningful). Minima and maxima occurring within the maps are indicated at the top right of the maps.

volume, with increasing heritability of white matter and decreasing heritability of gray matter across development (Lenroot et al., 2009). In the largest twin MRI study to date, individuals in the same age range as our study (age 12 years), the authors report heritability estimates were on average $\sim 0.5$, with values of 0.8 and higher not achieved until late adolescence (age 17 years). In contrast, we find a large number of regions and frequency bands in the sleep EEG that exhibit heritability values $>0.8$. Thus, the sleep EEG, a measure related to brain structure and function, exhibits even higher heritability than measures of cortical volume and our findings promote the sleep EEG as among the most heritable traits to be measured in humans (Polderman et al., 2015).

We find pronounced influence of genes, shared and unique environmental factors dependent on brain region and frequency band. This is not surprising given that each EEG frequency band is associated with somewhat unique neurocircuitry and function (Lopes da Silva, 1991) in a state-dependent manner. For example, the generation of sleep spindles relies heavily on the thalamus, such that a lesion in the thalamus eliminates spindles, but not slow waves (though the thalamus plays a role in shaping slow waves; Crunelli and Hughes, 2010).

We find clear topographic segregation of $\sigma$ power and to a lesser extent spindle amplitude and ISA with shared environmental factors influencing spindles in anterior regions, whereas genetic factors strongly shape anterior spindles. Further, we found that shared environmental factors also impact the duration and density of fast spindles, but not slow spindles. Slow spindle duration and density showed an impact of unique environmental factors over posterior regions. Studies in animals have shown that although spindles begin in the thalamus, thalamocortical cells play a critical role in determining the duration and density of sleep spindles (Bonjean et al., 2011; Barthó et al., 2014). These studies, however, did not examine slow and fast spindles separately nor did they examine the impact of topography on their findings. Therefore, the dissociation of the environmental contribution to slow and fast spindle duration and density remains unclear and should be examined in future studies. Nonetheless, examining most measures of spindles, be it $\sigma$ power, spindle 
NREM Sleep: Correlations
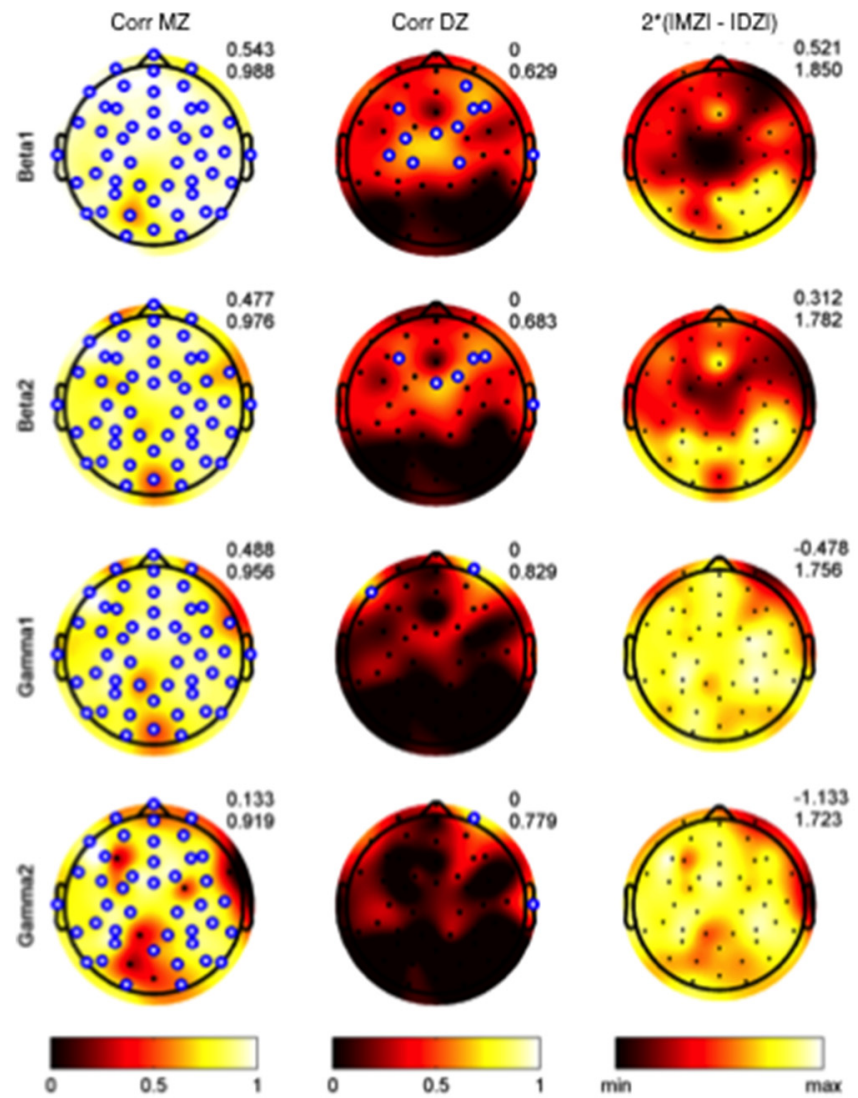
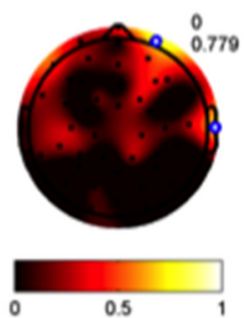

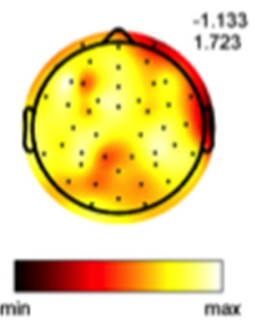

NREM Sleep: ICC
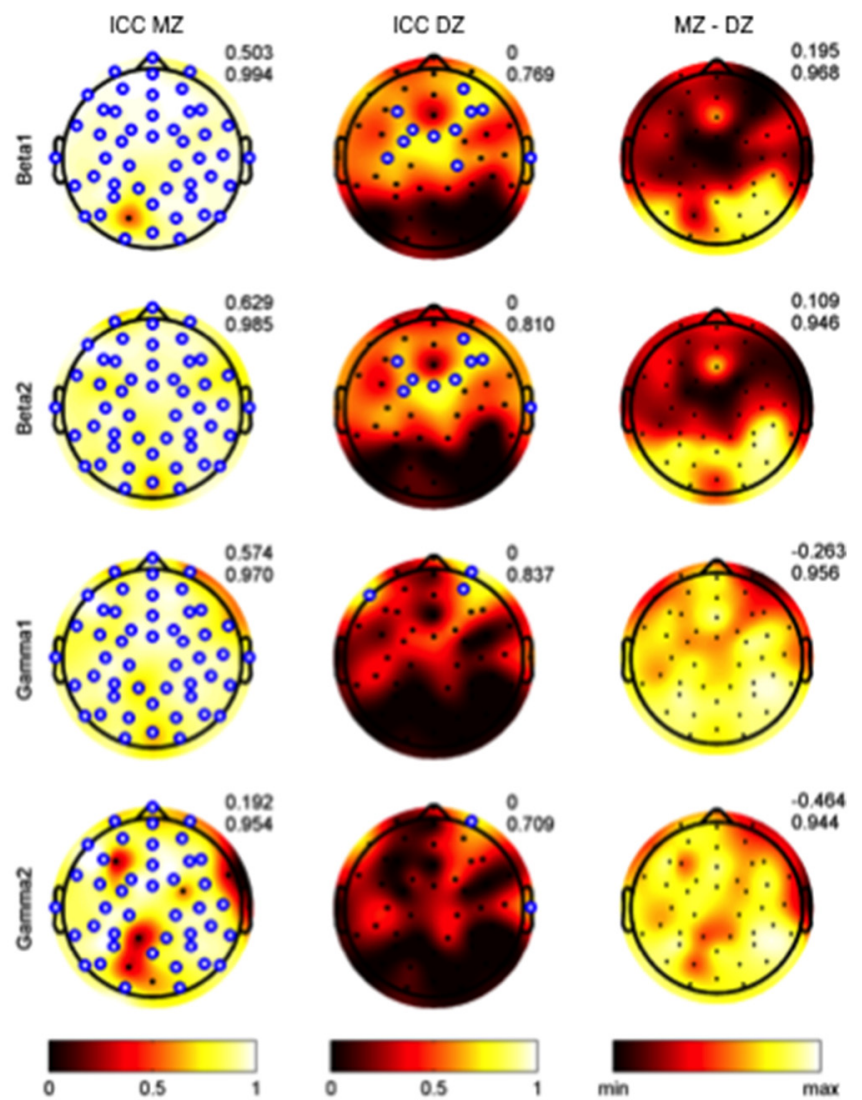

Figure 6. Pearson correlation coefficients (Corr; 3 leftmost plots) and ICCs (3 rightmost plots) for MZ and DZ twins for beta 1 ( $16.2-20 \mathrm{~Hz})$, beta 2 (20.2-24 Hz), gamma 1 ( $24.2-34 \mathrm{~Hz})$, and gamma $2(34.2-44 \mathrm{~Hz})$ power. Derivations exhibiting a significant correlation coefficient ( $r$ value) or ICC based on bootstrap statistic are shown with a blue circle, whereas nonsignificant correlations are shown with a black dot. Falconers heritability $\left(h^{2}\right)$ is shown in the last column for the correlation maps and the difference in ICC values between MZ and DZ twins is shown for the ICC maps ( $M Z$ Z DZ). Correlation and ICC maps were scaled between 0 and 1 because negative correlations and ICC values are not biologically meaningful and likely reflect noise. The difference in ICC values between $\mathrm{MZ}$ and DZ twins (i.e., $\mathrm{MZ}-\mathrm{DZ}$ ) and $h^{2}$ [i.e., $\left.2 \times(|\mathrm{MZ}|-|\mathrm{DZ}|)\right]$ for correlation coefficients are scaled between minima (min) and maxima (max); however, we note that negative values (i.e., instance where ICC and correlation values are larger in DZ compared with $\mathrm{MZ}$ twins are not biological meaningful). Minima and maxima occurring within the maps are indicated at the top right of the maps.

amplitude, or ISA we find an influence of shared environmental factors over anterior regions.

In addition to being implicated in psychiatric disorders, sleep spindles play a fundamental role in sleep-dependent learning and neural plasticity in the healthy brain. Our findings put previous studies into context, suggesting that deficits in posterior spindles are driven by genetic factors, whereas anterior spindles are modifiable through environmental influences. Differential mechanism of spindle generation may underlie the topographic segregation of genetic from environmental factors. Animal and human studies have shown that two types of thalamocortical projections, a core and a matrix pathway, contribute to topographically distinct spindles (Kim et al., 2015; Piantoni et al., 2016). The core pathway dominates over posterior (i.e., postcentral, occipital, and posterior temporal) regions, whereas spindles generated through the matrix pathway are more spatially diffuse and cover anterior regions. The differential mechanism of generation and topography of these two spindle classes may translate into a unique function for each spindle class. Our results suggest that the development of the core thalamocortical circuit is likely under strong genetic control, whereas matrix neurons can be molded based on environmental influence. Identifying shared environmental factors that may influence spindles in anterior regions is an important next step. For example, an enriched en- vironment in part ameliorates cognitive deficits in rats following a lesion of the anterior thalamic nuclei (Loukavenko et al., 2007; Wolff et al., 2008; Dupire et al., 2013), suggesting that sections of the thalamus may be sensitive to environmental influence. Thus, we hypothesize that matrix thalamic projections may be shaped through familial environment. Furthermore, the development of anterior brain regions is more protracted than posterior regions (Giedd et al., 1999), perhaps reflecting greater plasticity and responsiveness to environmental influences. We note that our findings may be specific to this developmental period where twins still live together and the impact of shared environment may be diminished or absent in adulthood.

Though genome-wide association studies (GWAS) have been performed for sleep disorders, sleep duration, and sleep phenotypes, studies examining the genetic basis of the sleep EEG are few (Sehgal and Mignot, 2011). However, given the ubiquity of findings implicating sleep spindles in psychiatric disorders and cognitive function, overlapping genes between these domains and spindles may exist and be a fruitful line of research. Our findings inform future studies and suggest that GWAS should focus on posterior compared with anterior spindles.

With regard to SO and SWA, we find that these oscillations are under strong genetic control over posterior regions. Interestingly, we find that environmental factors unique to each twin 
account for variance in SOs and to a lesser extent SWA, over frontal derivations. On a neuronal level, SOs are generated through periods of synchronous neural activity (On period) followed by periods of relative neural silence (Off period). Few studies in humans make a distinction between SOs and SWA, typically averaging over the entire frequency range. However, there is some evidence that these two bands may be functionally unique. For example, the topographic distribution of power somewhat differs for SOs and SWA (Bersagliere et al., 2018).

Nonetheless, we interpret the unique environmental influence on SOs and SWA in light of the synaptic homeostasis hypothesis (Tononi and Cirelli, 2006), which postulates that the function of slow waves is the rescaling of synapses following waking and the extensive literature showing the sensitivity of these oscillations to waking activity over a local cortical region (Huber et al., 2004). The frontal cortex is responsible for higher order cognitive function. Given that our sample consisted of students whose waking day is largely spent in school learning and problem solving, it is feasible that individual differences in workload during the waking day could translate to variance in the strength of slow waves. It remains unclear, however, why the contribution from unique environmental factors is stronger for SOs than SWA, however, our results suggest that future studies of sleepdependent learning examine SOs separately from SWA.

In contrast to a previous sleep EEG twin study (Ambrosius et al., 2008), we found high heritability estimates across scalp locations in the beta bands. These bands are typically overlooked in the sleep EEG literature due to concerns of contamination with artifacts. Indeed, we went to great effort to clean the current dataset to ensure high-quality data. In the waking EEG literature, the potential of resting state beta activity as an endophenotype has been recognized. Beta activity is thought to be important for cognitive functions reliant upon long-range connections (Donner and Siegel, 2011) and is associated with externalizing disorders (Gilmore et al., 2010), such as substance use disorder (Bauer, 2001; Rangaswamy et al., 2002) and ADHD (Barry et al., 2003). Based on a twin study in adolescents (mean age $=16.2$ years) the heritability of wake EEG beta power was estimated to be $86 \%$ (van Beijsterveldt et al., 1996). We find similar, and somewhat higher, heritability estimates in the sleep EEG in our younger sample of adolescents. Thus, beta power in the sleep EEG may also constitute an important endophenotype (Markovic et al., 2018a).

Direct comparison of our study with sleep EEG studies in adults is difficult because we used SEM combined with highdensity EEG recordings to quantify heritability patterns across the scalp. However, applying ICC analysis at the derivation used in the De Gennaro et al. (2008) paper (i.e., Cz; however we note the use of average reference in our data and average mastoid in their paper), we find ICC values in the same range (adults: $\mathrm{MZ}=$ 0.93; DZ = 0.46; adolescents: $\mathrm{MZ}=0.92 ; \mathrm{DZ}=0.4)$. Thus, even during a time when biology and behavior are in flux, the sleep EEG exhibits high heritability similar to what is observed in adults. Unlike the De Gennaro et al. (2008) study in adults, which found no interaction between zygosity (i.e., MZ vs DZ) and derivation (i.e., $\mathrm{Fz}, \mathrm{Pz}$, and $\mathrm{Cz}$ ), suggesting no topographic variation in heritability, we find strong topographic variation in heritability. Whether this is due to the different age groups studied or is a methodological difference should be addressed in future studies.

It is important to note that in addition to absolute power, the topographic distribution of power differs in adolescents compared with adults, with pronounced shifts in the region with maximal power across adolescent development (Kurth et al.,
2010; Markovic et al., 2018b ). For example, unlike SWA in adults, which has a frontal focus, SWA in our sample has a posterior as well as an anterior focus (Fig. 1), similar to what has been previously shown in this age range (Kurth et al., 2010). Although we do not find a direct correspondence between regions of maximal power and highest heritability (Figs. 1, 4), future high-density EEG studies in adults should clarify the relationship between heritability and the topographic distribution of power.

With regard to sleep stages, our heritability estimates of sleep latency and wake after sleep onset are very similar (within 5\%) to values measured using several weeks to months of actigraphy in early adolescents (Sletten et al., 2013; Inderkum and Tarokh, 2018). The impact of genetic factors on other sleep stage variables was minimal with REM sleep latency and slow-wave sleep showing moderate $(\approx 40 \%)$ heritability. In adults, REM sleep and slow-wave sleep show a modest genetic contribution (for review, see Tafti, 2009). The lower heritability of sleep stage variables compared with EEG spectral components is perhaps unsurprising given that sleep stages, unlike the EEG spectra, do not exhibit high intrasubject stability across multiple nights (Sharpley et al., 1990; Buckelmüller et al., 2006).

Some limitations of the study are important to note. First our sample size (total of 30 pairs) was limited, however, it was in the same range as the two other twin studies of sleep (De Gennaro et al., 2008, total of 20 pairs; Ambrosius et al., 2008, total of 51 pairs). Furthermore, because of the sample size we were unable to examine the impact of sex and age on our results. We, however, examine a narrow age range and only include same-sex twin pairs.

Given that sleep neurophysiology is altered in many neurodevelopmental and neuropsychiatric disorders, our finding of high heritability makes the sleep EEG an invaluable tool for studies hoping to find vulnerability markers to psychiatric disorders. This high heritability combined with the ease of measurement of an "offline" brain, unaffected by external parameters or internal states, make the sleep EEG an ideal biomarker to aid diagnostic classification, predict outcomes, and track treatment response in a neurodevelopmental population. Our findings have broad implications for neurology, neuroscience, and psychiatry, given the ubiquity of findings associating sleep and disorders of the brain.

\section{References}

Abel T, Havekes R, Saletin JM, Walker MP (2013) Sleep, plasticity and memory from molecules to whole-brain networks. Curr Biol 23:R774R788. CrossRef Medline

Ambrosius U, Lietzenmaier S, Wehrle R, Wichniak A, Kalus S, Winkelmann J, Bettecken T, Holsboer F, Yassouridis A, Friess E (2008) Heritability of sleep electroencephalogram. Biol Psychiatry 64:344-348. CrossRef Medline

Andrillon T, Nir Y, Staba RJ, Ferrarelli F, Cirelli C, Tononi G, Fried I (2011) Sleep spindles in humans: insights from intracranial EEG and unit recordings. J Neurosci 31:17821-17834. CrossRef Medline

Barry RJ, Clarke AR, Johnstone SJ (2003) A review of electrophysiology in attention-deficit/hyperactivity disorder: I. Qualitative and quantitative electroencephalography. Clin Neurophysiol 114:171-183. CrossRef Medline

Barthó P, Slézia A, Mátyás F, Faradzs-Zade L, Ulbert I, Harris KD, Acsády L (2014) Ongoing network state controls the length of sleep spindles via inhibitory activity. Neuron 82:1367-1379. CrossRef Medline

Bauer LO (2001) Predicting relapse to alcohol and drug abuse via quantitative electroencephalography. Neuropsychopharmacology 25:332-340. CrossRef Medline

Benz DC, Tarokh L, Achermann P, Loughran SP (2013) Regional differences in trait-like characteristics of the waking EEG in early adolescence. BMC Neurosci 14:117. CrossRef Medline

Bersagliere A, Pascual-Marqui RD, Tarokh L, Achermann P (2018) Map- 
ping slow waves by EEG topography and source localization: effects of sleep deprivation. Brain Topogr 31:257-269. CrossRef Medline

Bódizs R, Körmendi J, Rigó P, Lázár AS (2009) The individual adjustment method of sleep spindle analysis: methodological improvements and roots in the fingerprint paradigm. J Neurosci Methods 178:205-213. CrossRef Medline

Boker S, Neale M, Maes H, Wilde M, Spiegel M, Brick T, Spies J, Estabrook R, Kenny S, Bates T, Mehta P, Fox J (2011) OpenMx: an open source extended structural equation modeling framework. Psychometrika 76:306317. CrossRef Medline

Bonjean M, Baker T, Lemieux M, Timofeev I, Sejnowski T, Bazhenov M (2011) Corticothalamic feedback controls sleep spindle duration in vivo. J Neurosci 31:9124-9134. CrossRef Medline

Buchmann A, Ringli M, Kurth S, Schaerer M, Geiger A, Jenni OG, Huber R (2011) EEG sleep slow-wave activity as a mirror of cortical maturation. Cereb Cortex 21:607-615. CrossRef Medline

Buckelmüller J, Landolt HP, Stassen HH, Achermann P (2006) Trait-like individual differences in the human sleep electroencephalogram. Neuroscience 138:351-356. CrossRef Medline

Crunelli V, Hughes SW (2010) The slow $(<1 \mathrm{~Hz})$ rhythm of non-REM sleep: a dialogue between three cardinal oscillators. Nat Neurosci 13:917. CrossRef Medline

De Gennaro L, Ferrara M, Vecchio F, Curcio G, Bertini M (2005) An electroencephalographic fingerprint of human sleep. Neuroimage 26:114122. CrossRef Medline

De Gennaro L, Marzano C, Fratello F, Moroni F, Pellicciari MC, Ferlazzo F, Costa S, Couyoumdjian A, Curcio G, Sforza E, Malafosse A, Finelli LA, Pasqualetti P, Ferrara M, Bertini M, Rossini PM (2008) The electroencephalographic fingerprint of sleep is genetically determined: a twin study. Ann Neurol 64:455-460. CrossRef Medline

Dijk DJ, Hayes B, Czeisler CA (1993) Dynamics of electroencephalographic sleep spindles and slow wave activity in men: effect of sleep deprivation. Brain Res 626:190-199. CrossRef Medline

Donner TH, Siegel M (2011) A framework for local cortical oscillation patterns. Trends Cogn Sci 15:191-199. CrossRef Medline

Dupire A, Kant P, Mons N, Marchand AR, Coutureau E, Dalrymple-Alford J, Wolff M (2013) A role for anterior thalamic nuclei in affective cognition: interaction with environmental conditions. Hippocampus 23:392404. CrossRef Medline

Evans DM, Gillespie NA, Martin NG (2002) Biometrical genetics. Biol Psychol 61:33-51. CrossRef Medline

Fatemi SH, Folsom TD (2009) The neurodevelopmental hypothesis of schizophrenia, revisited. Schizophr Bull 35:528-548. CrossRef Medline

Ferrarelli F, Tononi G (2017) Reduced sleep spindle activity point to a TRN-MD thalamus-PFC circuit dysfunction in schizophrenia. Schizophr Res 180:36-43. CrossRef Medline

Ferrarelli F, Huber R, Peterson MJ, Massimini M, Murphy M, Riedner BA, Watson A, Bria P, Tononi G (2007) Reduced sleep spindle activity in schizophrenia patients. Am J Psychiatry 164:483-492. CrossRef Medline

Ferrarelli F, Peterson MJ, Sarasso S, Riedner BA, Murphy MJ, Benca RM, Bria P, Kalin NH, Tononi G (2010) Thalamic dysfunction in schizophrenia suggested by whole-night deficits in slow and fast spindles. Am J Psychiatry 167:1339-1348. CrossRef Medline

Finelli LA, Borbély AA, Achermann P (2001) Functional topography of the human nonREM sleep electroencephalogram. Eur J Neurosci 13:22822290. CrossRef Medline

Giedd JN, Blumenthal J, Jeffries NO, Castellanos FX, Liu H, Zijdenbos A, Paus T, Evans AC, Rapoport JL (1999) Brain development during childhood and adolescence: a longitudinal MRI study. Nat Neurosci 2:861-863. CrossRef Medline

Giedd JN, Raznahan A, Alexander-Bloch A, Schmitt E, Gogtay N, Rapoport JL (2015) Child psychiatry branch of the national institute of mental health longitudinal structural magnetic resonance imaging study of human brain development. Neuropsychopharmacology 40:43-49. CrossRef Medline

Gilmore CS, Malone SM, Iacono WG (2010) Brain electrophysiological endophenotypes for externalizing psychopathology: a multivariate approach. Behav Genet 40:186-200. CrossRef Medline

Huber R, Ghilardi MF, Massimini M, Tononi G (2004) Local sleep and learning. Nature 430:78-81. CrossRef Medline

Huguenard JR, McCormick DA (2007) Thalamic synchrony and dynamic regulation of global forebrain oscillations. Trends Neurosci 30:350-356. CrossRef Medline

Inderkum AP, Tarokh L (2018) High heritability of adolescent sleep-wake behavior on free, but not school days: a long-term twin study. Sleep 41: zsy004. CrossRef Medline

Keshavan MS, Reynolds CF 3rd, Miewald MJ, Montrose DM, Sweeney JA, Vasko RC Jr, Kupfer DJ (1998) Delta sleep deficits in schizophrenia: evidence from automated analyses of sleep data. Arch Gen Psychiatry 55:443-448. CrossRef Medline

Kim D, Hwang E, Lee M, Sung H, Choi JH (2015) Characterization of topographically specific sleep spindles in mice. Sleep 38:85-96. CrossRef Medline

Kitsune GL, Cheung CH, Brandeis D, Banaschewski T, Asherson P, McLoughlin G, Kuntsi J (2015) A matter of time: the influence of recording context on EEG spectral power in adolescents and young adults with ADHD. Brain Topogr 28:580-590. CrossRef Medline

Kurth S, Ringli M, Geiger A, LeBourgeois M, Jenni OG, Huber R (2010) Mapping of cortical activity in the first two decades of life: a high-density sleep electroencephalogram study. J Neurosci 30:13211-13219. CrossRef Medline

Lenroot RK, Schmitt JE, Ordaz SJ, Wallace GL, Neale MC, Lerch JP, Kendler KS, Evans AC, Giedd JN (2009) Differences in genetic and environmental influences on the human cerebral cortex associated with development during childhood and adolescence. Hum Brain Mapp 30:163-174. CrossRef Medline

Lopes da Silva F (1991) Neural mechanisms underlying brain waves: from neural membranes to networks. Electroencephalogr Clin Neurophysiol 79:81-93. CrossRef Medline

Loukavenko EA, Ottley MC, Moran JP, Wolff M, Dalrymple-Alford JC (2007) Towards therapy to relieve memory impairment after anterior thalamic lesions: improved spatial working memory after immediate and delayed postoperative enrichment. Eur J Neurosci 26:3267-3276. CrossRef Medline

Lüthi A (2014) Sleep spindles: where they come from, what they do. Neuroscientist 20:243-256. CrossRef Medline

Mander BA, Marks SM, Vogel JW, Rao V, Lu B, Saletin JM, Ancoli-Israel S, Jagust WJ, Walker MP (2015) beta-amyloid disrupts human NREM slow waves and related hippocampus-dependent memory consolidation. Nat Neurosci 18:1051-1057. CrossRef Medline

Manoach DS, Pan JQ, Purcell SM, Stickgold R (2016) Reduced sleep spindles in schizophrenia: a treatable endophenotype that links risk genes to impaired cognition? Biol Psychiatry 80:599-608. CrossRef Medline

Maris E, Oostenveld R (2007) Nonparametric statistical testing of EEG- and MEG-data. J Neurosci Methods 164:177-190. CrossRef Medline

Markovic A, Achermann P, Rusterholz T, Tarokh L (2018a) Heritability of sleep EEG topography in adolescence: results from a longitudinal twin study. Sci Rep 8:7334. CrossRef Medline

Markovic A, Rusterholz T, Achermann P, Tarokh L (2018b) Heritability of topographic distribution of sleep EEG power in early adolescents. Sci Rep 8:7334. CrossRef

McClain IJ, Lustenberger C, Achermann P, Lassonde JM, Kurth S, LeBourgeois MK (2016) Developmental changes in sleep spindle characteristics and sigma power across early childhood. Neural Plasticity 2016:3670951. CrossRef Medline

Pernet CR, Latinus M, Nichols TE, Rousselet GA (2015) Cluster-based computational methods for mass univariate analyses of event-related brain potentials/fields: a simulation study. J Neurosci Methods 250:8593. CrossRef Medline

Piantoni G, Halgren E, Cash SS (2016) The contribution of thalamocortical core and matrix pathways to sleep spindles. Neural Plasticity 2016: 3024342. CrossRef Medline

Polderman TJ, Benyamin B, de Leeuw CA, Sullivan PF, van Bochoven A, Visscher PM, Posthuma D (2015) Meta-analysis of the heritability of human traits based on fifty years of twin studies. Nat Genet 47:702-709. CrossRef Medline

Rangaswamy M, Porjesz B, Chorlian DB, Wang K, Jones KA, Bauer LO, Rohrbaugh J, O'Connor SJ, Kuperman S, Reich T, Begleiter H (2002) Beta power in the EEG of alcoholics. Biol Psychiatry 52:831-842. CrossRef Medline

Rechtschaffen A, Kales A (1968) A manual of standardized terminology, techniques and scoring system for sleep stages of human subjects. Los Angeles: UCLA Brain Information Service/Brain Research Institute. 
Rijsdijk FV, Sham PC (2002) Analytic approaches to twin data using structural equation models. Brief Bioinform 3:119-133. CrossRef Medline

Rosanova M, Ulrich D (2005) Pattern-specific associative long-term potentiation induced by a sleep spindle-related spike train. J Neurosci 25:93989405. CrossRef Medline

Sehgal A, Mignot E (2011) Genetics of sleep and sleep disorders. Cell 146: 194-207. CrossRef Medline

Sekimoto M, Kato M, Watanabe T, Kajimura N, Takahashi K (2007) Reduced frontal asymmetry of delta waves during all-night sleep in schizophrenia. Schizophr Bull 33:1307-1311. CrossRef Medline

Sharpley AL, Solomon RA, Cowen PJ (1990) Sleep stability with home sleep recording and automatic sleep stage analysis. Sleep 13:538-540. CrossRef Medline

Sletten TL, Rajaratnam SM, Wright MJ, Zhu G, Naismith S, Martin NG, Hickie I (2013) Genetic and environmental contributions to sleep-wake behavior in 12-year-old twins. Sleep 36:1715-1722. CrossRef Medline

Steriade M (2006) Grouping of brain rhythms in corticothalamic systems. Neuroscience 137:1087-1106. CrossRef Medline

Tafti M (2009) Genetic aspects of normal and disturbed sleep. Sleep Med 10:S17-S21. CrossRef Medline

Tarokh L, Carskadon MA, Achermann P (2011) Trait-like characteristics of the sleep EEG across adolescent development. J Neurosci 31:6371-6378. CrossRef Medline

Tesler N, Gerstenberg M, Franscini M, Jenni OG, Walitza S, Huber R (2016) Increased frontal sleep slow wave activity in adolescents with major depression. Neuroimage Clin 10:250-256. CrossRef Medline

Tinguely G, Finelli LA, Landolt HP, Borbély AA, Achermann P (2006)
Functional EEG topography in sleep and waking: state-dependent and state-independent features. Neuroimage 32:283-292. CrossRef Medline

Tononi G, Cirelli C (2006) Sleep function and synaptic homeostasis. Sleep Med Rev 10:49-62. CrossRef Medline

Ujma PP, Sándor P, Szakadát S, Gombos F, Bódizs R (2016) Sleep spindles and intelligence in early childhood-developmental and trait-dependent aspects. Dev Psychol 52:2118-2129. CrossRef Medline

van Beijsterveldt CE, Molenaar PC, de Geus EJ, Boomsma DI (1996) Heritability of human brain functioning as assessed by electroencephalography. Am J Hum Genet 58:562-573. Medline

Warby SC, Wendt SL, Welinder P, Munk EG, Carrillo O, Sorensen HB, Jennum P, Peppard PE, Perona P, Mignot E (2014) Sleep-spindle detection: crowdsourcing and evaluating performance of experts, non-experts and automated methods. Nat Methods 11:385-392. CrossRef Medline

Werth E, Achermann P, Dijk DJ, Borbély AA (1997) Spindle frequency activity in the sleep EEG: individual differences and topographic distribution. Electroencephalogr Clin Neurophysiol 103:535-542. CrossRef Medline

Wolff M, Loukavenko EA, Will BE, Dalrymple-Alford JC (2008) The extended hippocampal-diencephalic memory system: enriched housing promotes recovery of the flexible use of spatial representations after anterior thalamic lesions. Hippocampus 18:996-1007. CrossRef Medline

Yang J, Huang T, Petralia F, Long Q, Zhang B, Argmann C, Zhao Y, Mobbs CV, Schadt EE, Zhu J, Tu Z; GTEx Consortium (2016) Corrigendum: synchronized age-related gene expression changes across multiple tissues in human and the link to complex diseases. Sci Rep 6:19384. CrossRef Medline 